\title{
EVALUATION OF THE REMOVAL OF TETRACYCLINE FLUORESCENCE FROM SPERMATOZOA AS A TEST FOR CAPACITATION IN THE RABBIT
}

\author{
R. A. VAIDYA, J. M. BEDFORD*, R. H. GLASS AND J. McL. MORRIS
}

Department of Obstetrics and Gynecology, Yale University School of Medicine, New Haven, Connecticut, and *Department of Anatomy and International Institute for Study of Human Reproduction, Columbia University College of Physicians and Surgeons, New York

(Received 13th Fuly 1968)

Summary. Removal of tetracycline fluorescence has been suggested as a test for capacitation. In the present study, a comparison is made of the time required to complete capacitation in either the uterus or the Fallopian tube, and the time in which fluorescence is lost from spermatozoa in these organs.

Capacitation requires at least 10 to $11 \mathrm{hr}$ in the Fallopian tube, and a similar period is required for complete capacitation in the oestrous uterus, but tetracycline fluorescence is lost from spermatozoa in these sites within $2 \mathrm{hr}$, one fifth of the period required for capacitation. Fluorescence is not removed from spermatozoa in the uterus of immature, mature ovariectomized, pseudopregnant or progesterone-treated females, or from spermatozoa in the anterior chamber of the eye, colon or bladder; though partial capacitation occurs to a varying but significant degree in all of these sites.

It is concluded that removal of tetracycline fluorescence from spermatozoa in the female tract is not a visible concomitant of their functional capacitation.

\section{INTRODUCTION}

The discovery that mammalian spermatozoa must spend some hours in the female tract before acquiring the capacity to penetrate ova (Chang, 1951; Austin, 1951) has focused attention on the physiological relationship between spermatozoa and the various regions of the female reproductive tract. The requirement for sperm capacitation in terms of the endocrine environment and of time has been studied using biological methods (Chang, 1955, 1958; Bedford, 1967; Hamner \& Sojka, 1967; Soupart, 1967), which always depend upon fertilization as the criterion of capacitation. The results have occasionally appeared contradictory, partly as a consequence of variation in the timing of insemination in relation to the post-ovulatory age of the egg. The use of a fluorometric method to indicate capacitation was suggested by Ericsson (1967a), 
who labelled spermatozoa with tetracycline hydrochloride. The label was removed from spermatozoa in situations where capacitation had been achieved, and remained in circumstances in which capacitation failed to occur.

Data showing the time of removal of fluorescence from rabbit spermatozoa in different environmental circumstances, and the time at which capacitated spermatozoa first appear in different regions of the female tract are presented. An evaluation of the removal of such a fluorescent label from spermatozoa as an objective indicator of the development of the capacitated state in rabbit spermatozoa is made on the basis of these data.

\section{Fluorescent labelling}

\section{METHODS}

Ejaculated spermatozoa from fertile males (Dutch-belted or New Zealand) were incubated for $10 \mathrm{~min}$ with 4 to $6 \mu \mathrm{g}$ of tetracycline hydrochloride $/ 1 \times 10^{6}$ spermatozoa, as described by Ericsson (1967a, b), and were then centrifuged for $10 \mathrm{~min}$ at $3000 \mathrm{rev} / \mathrm{min}$. The supernatant was discarded and the spermatozoa were resuspended in Tyrode's solution. These tetracycline-labelled spermatozoa showed a green fluorescence when viewed with ultra-violet light.

Labelled spermatozoa were then injected into recipient females either directly into the uterus through a mid-line abdominal incision (25 to $50 \times 10^{6}$ spermatozoa/horn in $0.25 \mathrm{ml}$ ) or through the fimbriated ostium into the ampulla of the oviduct by way of a flank incision $\left(0.5\right.$ to $1 \times 10^{6}$ spermatozoa/oviduct in 0.05 to $0.1 \mathrm{ml}$ ). Spermatozoa were left in vivo in these sites for periods ranging from 1 to $24 \mathrm{hr}$ before flushing the uterus or oviduct with Tyrode's solution to recover them. The spermatozoa were examined on glass slides for fluorescence, using a Leitz Ortholux microscope equipped with an HB 200 mercury burner and dark field condenser, in conjunction with a BG 38 heat filter, a UG 1 UV filter and a K 430 or K 460 barrier filter. Tetracycline-labelled spermatozoa were also kept in Tyrode's solution in vitro at $37^{\circ} \mathrm{C}$ for up to $48 \mathrm{hr}$ as controls and were examined to verify the persistence of the fluorescence.

Seven groups of females, mostly Dutch-belted does, were used as sperm recipients.

Group 1. Oestrus. Oestrous does were given an intravenous injection of 75 i.u. of human chorionic gonadotrophin HCG (APL, Ayerst Laboratories) at the time of insemination.

Group 2. Pseudopregnant. These animals were given 75 i.u. of HCG 8 to 10 days before insemination. The presence of functional corpora lutea was confirmed at the time of surgery.

Group 3. Ovariectomized. Mature animals were ovariectomized through flank incisions and were used 3 weeks after operation.

Group 4. Progesterone-treated. Mature does were given progesterone (Schering Corporation), 1 to $2 \mathrm{mg} / \mathrm{kg}$ body weight, by daily subcutaneous injection for 3 days. On the 3 rd day, each female was inseminated and 75 i.u. HCG were given intravenously at the time of insemination.

Group 5. Immature. These animals, 4 to 6 weeks of age, received one intravenous injection of 25 to 75 i.u. HCG at the time of insemination.

Group 6. Immature: primed with oestrogen. As in Group 5 above, but treated 
for 3 consecutive days with a daily intravenous injection of oestrone sulphate (Premarin, Ayerst Laboratories) $1 \mathrm{mg} / \mathrm{kg}$ body weight. On the 3rd day, an intravenous injection of 25 to 75 i.u. HCG was given in one.dose.

Group 7. Oestrus: with occlusion of utero-tubal junction. Oestrous does, in which the utero-tubal junction had been ligated bilaterally 3 weeks previously, were given an intravenous injection of 75 i.u. of HGG at the time of insemination.

With the exception of Groups 2 and 3, labelled spermatozoa were inseminated at the time of HCG administration.

\section{Capacitation experiments}

Oestrous females were each mated to three fertile males. In some females, one or both oviducts had been occluded at the utero-tubal junction 3 weeks previously. Ova for transfer were recovered by flushing the oviducts of donors with Ringer solution, 12 to $12 \frac{1}{2} \mathrm{hr}$ after an ovulating injection of HGG. These fresh ova were introduced through the cervical canal into the uterine lumen of a mated female, either $4 \frac{1}{2}, 7,9,12$ to 13 , or 16 to $18 \mathrm{hr}$ after mating. A ligature was placed immediately above the cervix to prevent loss of ova into the vagina. The uterine ova were recovered 6 to $6 \frac{1}{2} \mathrm{hr}$ later at the termination of their estimated fertile life and were observed in the living state with a phase contrast microscope. After fixing in acetic alcohol and staining with $1 \%$ lacmoid in $45 \%$ acetic acid, the stained ova were examined especially for the stage of formation of pronuclei, and for the fertilizing sperm tail in the ooplasm. Particular note was taken of the presence of motile or non-motile spermatozoa adhering to the surface of eggs which showed no sign of activation.

\section{RESULTS}

\section{Removal of tetracycline fluorescence}

Relationship to endocrine status. Labelled, non-motile and sluggish spermatozoa were fluorescent over the whole surface of the cell, the midpiece being the brightest area, but it was often difficult to ascertain fluorescence of actively motile spermatozoa.

The fluorescent label was removed in the uterus of adult oestrous does and oestrogen-treated immature does, but spermatozoa retained the label in the uterus of pseudopregnant, progesterone-treated, ovariectomized and immature females (Table 1). In all cases, the label was removed from spermatozoa in the Fallopian tube, irrespective of the hormonal status or age of the female.

In experimental situations in which the label was removed, there was no evidence of even minimal residual fluorescence. No attempt was made to quantitate the fluorescence, but this generally appeared brighter in spermatozoa recovered from the uterus of immature animals, than from pseudopregnant, progesterone-treated or ovariectomized females. The spermatozoa recovered from immature uteri appeared to fluoresce as brightly as did those in the control samples.

Influence of time. Early experiments showed that the fluorescent label was removed from spermatozoa in the oestrous uterus within $6 \mathrm{hr}$. A reduction in the period of incubation showed that the label still persisted in the oestrous uterus 
after $1 \mathrm{hr}$ but was removed within $2 \mathrm{hr}$, regardless of the patency of the uterotubal junction. The same was true for spermatozoa in the Fallopian tube.

Tetracycline fluorescence was not removed from spermatozoa remaining in immature or pseudopregnant uteri 12 and $24 \mathrm{hr}$, respectively (Plate 1). Incubation of labelled spermatozoa in vitro at $37^{\circ} \mathrm{C}$ in Tyrode's solution for up to $48 \mathrm{hr}$ in no way reduced the intensity of their fluorescence.

TABLE 1

FATE OF TETRAGYGLINE LABEL ON SPERMATOZOA IN UTERUS OR OVIDUCT OF THE RABBIT

\begin{tabular}{|c|c|c|c|}
\hline Location & No. of does & $H r$ & $\begin{array}{l}\text { Spermatozoal } \\
\text { fluorescence }\end{array}$ \\
\hline $\begin{array}{l}\text { 1. Uterus } \\
\text { Oestrus }\end{array}$ & $\begin{array}{l}3 \\
7\end{array}$ & $\begin{array}{l}2 \\
6\end{array}$ & $\begin{array}{l}0 \\
0\end{array}$ \\
\hline Oestrus with uterus separated from oviduct & 2 & 2 & 0 \\
\hline Pseudopregnant & $\begin{array}{l}4 \\
2\end{array}$ & $\begin{array}{r}6 \\
24\end{array}$ & + \\
\hline Progesterone-treated & 3 & 6 & + \\
\hline Immature & 12 & 12 & + \\
\hline Immature oestrogen-treated & $\begin{array}{l}1 \\
3\end{array}$ & $\begin{array}{l}2 \\
6\end{array}$ & $\begin{array}{l}0 \\
0\end{array}$ \\
\hline Ovariectomized rabbit & 3 & 6 & + \\
\hline $\begin{array}{l}\text { 2. Oviduct } \\
\text { Oestrus }\end{array}$ & $\begin{array}{l}2 \\
4\end{array}$ & $\begin{array}{l}2 \\
6\end{array}$ & $\begin{array}{l}0 \\
0\end{array}$ \\
\hline Pseudopregnant & $\begin{array}{l}2 \\
1\end{array}$ & $\begin{array}{l}2 \\
6\end{array}$ & $\begin{array}{l}0 \\
0\end{array}$ \\
\hline Ovariectomized rabbit & $\begin{array}{l}2 \\
1\end{array}$ & $\begin{array}{l}2 \\
6\end{array}$ & $\begin{array}{l}0 \\
0\end{array}$ \\
\hline Immature & $\begin{array}{l}1 \\
1\end{array}$ & $\begin{array}{l}2 \\
6\end{array}$ & $\begin{array}{l}0 \\
0\end{array}$ \\
\hline 3. Incubated in Tyrode's solution at $37^{\circ} \mathrm{C}$ & & 48 & + \\
\hline
\end{tabular}

$+=$ Fluorescence retained; $0=$ fluorescence lost.

\section{Capacitation in the uterus}

Ova were placed in the uterus $4 \frac{1}{2} \mathrm{hr}$ after mating in four initial experiments. Although these ova had many motile spermatozoa adherent to the surface when recovered from the uterus 6 to $6 \frac{1}{2} \mathrm{hr}$ later, none had been fertilized. Similar results were obtained in five experiments when thirteen ova were introduced into the uterus $7 \mathrm{hr}$ after mating, except that in one experiment, five ova were found to have been penetrated when recovered $6 \mathrm{hr}$ later. These five penetrated ova all displayed a meiotic spindle in late telophase, and in each case the head of the fertilizing spermatozoon had begun to undergo the characteristic swelling phase which precedes the formation of the definitive pronucleus, indicating that sperm penetration must have occurred only shortly before recovery of the ova.

Introduction of ova into the uterus at $9 \mathrm{hr}$ after coitus in four experiments resulted in thirty-one of forty-eight ova $(65 \%)$ being fertilized. In many of these 


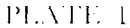

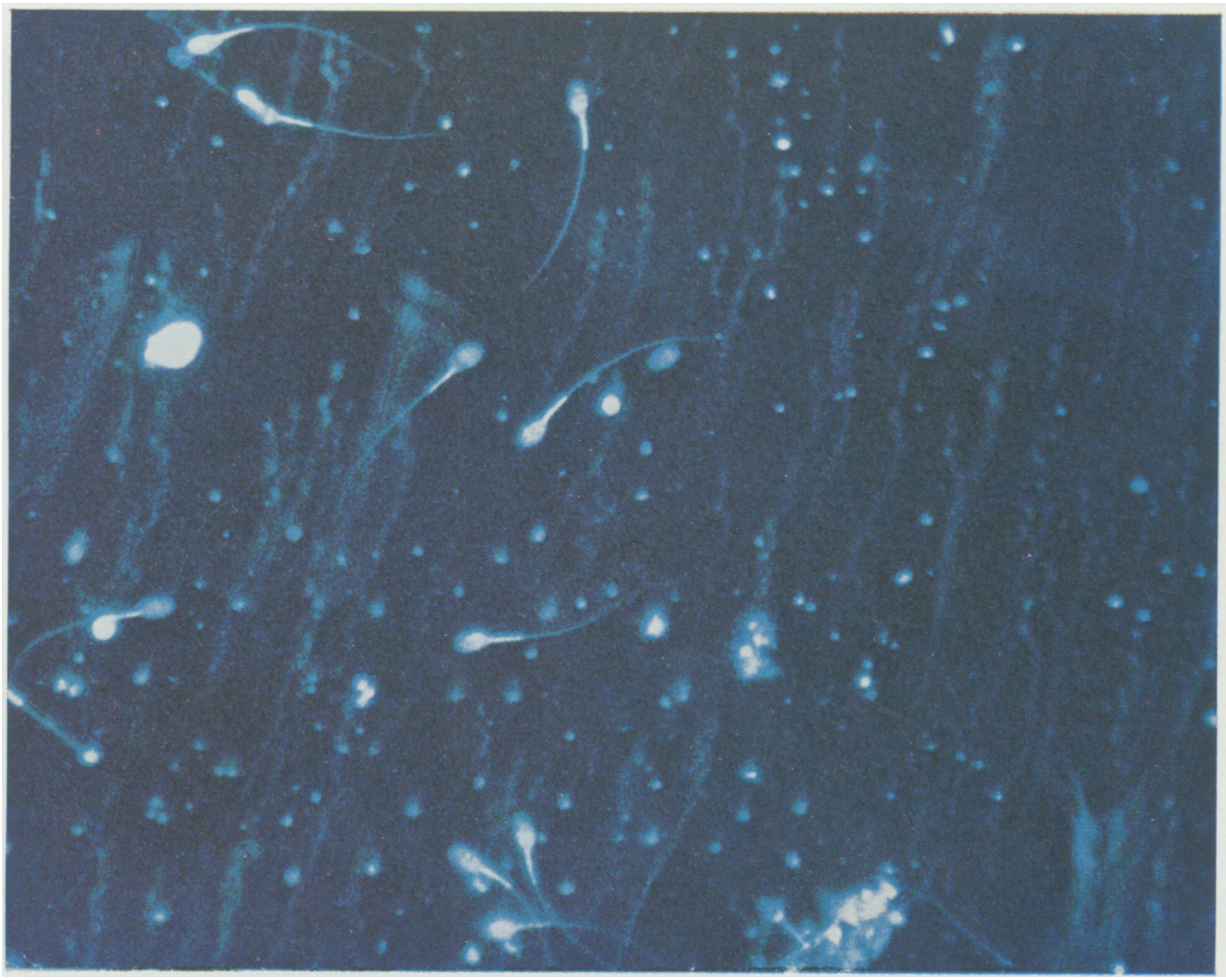

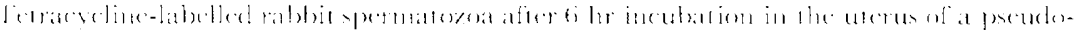
1). 
fertilized eggs recovered after $6 \mathrm{hr}$ in the uterus, two small pronuclei were present, but in most instances these had not yet come into apposition. Several fertilized eggs in this group also showed a somewhat earlier stage of development in which the male pronucleus had partially formed as an elongated body, or in which the sperm head had reached only the earlier swelling stage.

When ova were instilled into the normal uterus in seven experiments as late as 12 to $12 \frac{1}{2} \mathrm{hr}$ after mating, thirty-two of thirty-four recovered ova $(94 \%)$ were fertilized. In this latter group, fertilization evidently had occurred normally and promptly since most ova, recovered after $6 \mathrm{hr}$ in the uterus, possessed a fully formed male and a female pronucleus lying in close apposition usually in the centre of the egg. By contrast, only $13.5 \%$ (seven of fifty-two eggs in ten experiments) were fertilized when placed 12 to $13 \mathrm{hr}$ after coitus into uterine horns from which the oviduct had been separated 3 weeks previously. These few fertilized eggs were found to be at a relatively early stage of development after $6 \mathrm{hr}$ in the isolated uterus. Only when eggs were placed in such an isolated uterus as long as $16 \frac{1}{2}$ to $18 \mathrm{hr}$ after normal mating, were a high percentage fertilized $(89.5 \%$, thirty-three of thirty-seven eggs in three experiments).

\section{DISCUSSION}

Ericsson (1967b) stated that "it is assumed that removal of T-HCl from rabbit, bull and human spermatozoa indicates capacitation," and observation of the removal of fluorescence from rhesus monkey spermatozoa in the monkey oviduct, and in the uteri of some other species has been advanced as evidence of their capacitation (Dukelow \& Chernoff, 1968). Critical examination of the data obtained in the present study, however, makes it clear that the time of removal of the fluorescent label does not coincide with the development of the capacitated state in rabbit spermatozoa in the reproductive tract. Since the label was removed from spermatozoa in the uterus of the oestrous rabbit in approximately one fifth, or less, of the time required for this functional change, disappearance of bound fluorescence from rabbit spermatozoa in the uterus cannot be accepted as an indication of capacitation. Lack of any correlation between the time of removal of the label and the advent of the capacitated state, is further emphasized by the results obtained in animals in which the utero-tubal junction had been separated some 3 weeks previously. Such a separation had no effect on the histological appearance of the endometrium, or on the time at which the fluorescent label was removed from spermatozoa in the uterine lumen. Yet, as judged by the time of penetration of uterine ova, occlusion of the uterotubal junction delayed the appearance of fully capacitated spermatozoa in the uterus until about $15 \mathrm{hr}$ after mating. While these latter results show that, in the rabbit, capacitation can ultimately be completed in the uterus alone,

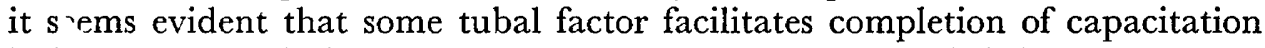
in 10 to $11 \mathrm{hr}$ within the normal uterus. In this context, it is interesting that approximately $20 \%$ of tubal secretions in the sheep pass in a retrograde manner into the uterus rather than into the abdominal cavity at the time of ovulation (Belve \& McDonald, 1968), but nothing appears to be known with certainty of the fate of tubal secretions in the rabbit. 
A similar lack of correlation exists between the accomplishment of capacitation and the removal of fluorescence from spermatozoa in the Fallopian tube. Spermatozoa require a capacitation period of at least $10 \mathrm{hr}$ in the rabbit Fallopian tube (Adams \& Chang, 1962) and ovariectomy substantially reduces the ability of the tube to accomplish capacitation (Bedford, 1968) but even in ovariectomized does the tube still remains competent to remove the fluorescent label from spermatozoa within $2 \mathrm{hr}$ (Table 1).

Removal of the fluorescent label might be considered a manifestation of an initial stage of the capacitation process which does not appear to be a single stage phenomenon in the rabbit (Bedford, 1967). But the label on spermatozoa remaining in the pseudopregnant uterus for as long as $24 \mathrm{hr}$ is unchanged (Table 1), though capacitation is definitely initiated within 14 to $20 \mathrm{hr}$ (Bedford, 1967). Likewise, the fluorescent label remains undiminished on spermatozoa in the immature or ovariectomized uterus for 6 to $12 \mathrm{hr}$ and is not removed in several other sites (Ericsson, 1967a), in all of which, a significant initial phase of capacitation is accomplished when judged from the period required by spermatozoa to complete the process and fertilize eggs in the Fallopian tube of a recipient female (Chang, 1958; Noyes, Walton \& Adams, 1958).

Ericsson (1967a) has shown by careful controls that disappearance of fluorescence involves loss and not merely quenching of the tetracycline hydrochloride. It is possible that the binding factors for tetracycline hydrochloride on the sperm-surface might be affected by one or more enzymes unrelated to the biochemical factors involved in capacitation. The activity of a few specific enzymes in the uterine secretions, including endo-peptidases (Albers, Bedford \& Chang, 1961) and glycerylphosphorylcholine diesterase (Wallace \& White, 1965) have been shown to vary with the endocrine status of the female. It seems reasonable to suppose that others might also show differences in their activity and concentration in response to oestrogenic and to progestational steroids.

\section{ACKNOWLEDGMENTS}

This study was supported in part by grants from the Lalor Foundation, the Ford Foundation and The National Cancer Institute, National Institutes of Health (CA 10749) (JMB).

The authors are grateful to Dr R. J. Ericsson, The Upjohn Company, for demonstrating the tetracycline labelling technique and for a generous supply of tetracycline $\mathrm{HCl}$.

Thanks are due to Mrs Carmen Vanegas and Miss S. Wallbanks for technical assistance.

\section{REFERENCES}

Adams, C. E. \& Chang, M. C. (1962) Capacitation of rabbit spermatozoa in the Fallopian tube and in the uterus. F. exp. Zool. 151, 159.

Albers, H. J., BeDFord, J. M. \& ChANG, M. C. (1961) Uterine peptidase activity in the rat ane $\mathcal{f}_{\text {abbit }}$ during pseudopregnancy. Am. F. Physiol. 201, 554.

Austin, C. R. (1951) Observations on the penetration of sperm into the mammalian egg. Aust. F. scient. Res. B, 4, 581 .

BEDFord, J. M. (1967) Experimental requirement for capacitation and observations on ultra-structural changes in rabbit spermatozoa during fertilization. F. Reprod. Fert. Suppl. 2, 35. 
BEDFoRd, J. M. (1968) Estrogen dependence of sperm capacitation in the rabbit Fallopian tube. (Abstract). Anat. Rec. 160, 312.

Belve, A. R. \& McDonald, M. F. (1968) Directional flow of Fallopian tube secretion in the Romney ewe. J. Reprod. Fert. 15, 357.

Chang, M. C. (1951) Fertilizing capacity of spermatozoa deposited into the Fallopian tubes. Nature, Lond. 168, 697.

Chang, M. G. (1955) Development of fertilizing capacity of rabbit spermatozoa in the uterus. Nature, Lond. 175, 1036.

Chang, M. G. (1958) Capacitation of rabbit spermatozoa in the uterus with special reference to reproductive phases of the female. Endocrinology, 63,619.

Dukelow, W. R. \& Chernoff, H. N. (1968) Primate sperm capacitation. (Abstract). Fedn Proc. Fedn Am. Socs exp. Biol. 27, 567.

ERICsson, R. J. (1967a) A fluorometric method for measurement of sperm capacitation. Proc. Soc. exp. Biol. Med. 125, 1115 .

ERICsson, R. J. (1967b) Technology, physiology and morphology of spermatozoa capacitation. J. Reprod. Fert. Suppl. 2, 65.

HAMNER, C. E. \& SojKA, N. J. (1967) Capacitation of rabbit spermatozoa: species specificity and organ specificity. Proc. Soc. exp. Biol. Med. 124, 689.

Noyes, R. W., Walton, A. \& Adams, G. E. (1958) Capacitation of rabbit spermatozoa. F. Endocr. 17, 374.

Soupart, P. (1967) Studies on the hormonal control of rabbit sperm capacitation. J. Reprod. Fert. Suppl. 2, 49.

Wallace, J. C. \& White, I. G. (1965) Studies of glycerylphosphorylcholine diesterase in the female reproductive tract. F. Reprod. Fert. $9,163$. 